Lehrbuch Romanistik 
Frank-Rutger Hausmann

\section{Französische Renaissance}

Lehrbuch Romanistik

\section{Verlag J.B. Metzler Stuttgart - Weimar}


Frank-Rutger Hausmann, geb. 1943, lehrt seit 1976 als Professor für französische und italienische Literatur in Aachen und Freiburg i.Br.

Bei J.B. Metzler sind erschienen: François Rabelais SM 176. 1979; Französisches Mittelalter. Lehrbuch Romanistik. 1996; Mitautor der Einführung in die französische Literaturwissenschaft SM 148. 4. Auflage 1997; der Französischen Literaturgeschichte. 3. Auflage 1994; der Italienischen Literaturgeschichte. 2. Auflage 1994; Mitarbeit am Metzler Philosophenlexikon. 2. Auflage 1995 u.a. Sammelwerken.

Die Deutsche Bibliothek - CIP-Einheitsaufnahme

Hausmann, Frank-Rutger:

Französische Renaissance / Frank-Rutger Hausmann. -

Stuttgart; Weimar: Metzler, 1997

(Lehrbuch Romanistik)

ISBN 978-3-476-01521-1

ISBN 978-3-476-01521-1

ISBN 978-3-476-03685-8 (eBook)

DOI 10.1007/978-3-476-03685-8

Dieses Werk einschließlich aller seiner Teile ist urheberrechtlich geschützt. Jede Verwertung außerhalb der engen Grenzen des Urheberrechtsgesetzes ist ohne Zustimmung des Verlages unzulässig und strafbar. Das gilt insbesondere für Vervielfältigungen, Übersetzungen, Mikroverfilmungen und die Einspeicherung und Verarbeitung in elektronischen Systemen.

(C) 1997 Springer-Verlag GmbH Deutschland

Ursprünglich erschienen bei J. B. Metzlersche Verlagsbuchhandlung und Carl Ernst Poeschel Verlag GmbH in Stuttgart 1997 


\section{INHALT}

Vorwort

I. Begriff und Wirklichkeit der Renaissance

Renaissance, Humanismus, Reformation ...................................... 1

Der Renaissancismus des 19. Jahrhunderts .................................. 6

Der italienische Renaissancehumanismus ...................................... 10

Renaissance und Humanismus in Frankreich ................................. 18

Die Selbsteinschätzung der französischen Humanisten ..................... 25

II. Politische Geschichte Frankreichs im 16. Jahrhundert

Der Hundertjährige Krieg ......................................................... 29

Die Italienkriege .................................................................. 33

Geschichtsschreiber des 15. Jahrhunderts ................................. 37

Die Religionskriege ............................................................... 39

Die Religionskriege im Spiegel der Literatur ................................. 44

Die Entdeckungen - die Franzosen in Nordamerika ...................... 48

Reisen und Entdeckungen bei Rabelais, Marguerite de Navarre und Montaigne ................................................................... 53

III. Italien und Frankreich

Der italienische Einfluß in Frankreich an der Wende

vom 15. zum 16. Jahrhundert .................................................. 56

Lyon als Schnittpunkt der Kulturen .......................................... 57

Berühmte Lyon-Besucher - Rabelais, Dolet, Marot........................ 60

Die Lyoneser Schule ............................................................. 66

Italienerlebnis und Italienerfahrung - Rabelais, Du Bellay,

Montaigne .................................................................. 72

Italienische Künstler in Frankreich ........................................... 82

Übersetzungen aus dem Italienischen ........................................... 84

Die Poetiken ......................................................................... 87

Erwachendes Keltentum ........................................................... 90

IV. Das neue Bildungsideal

Das Erbe der Antike .................................................................... 94

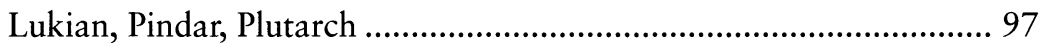

Der Einfluß der antiken Mythologie .......................................... 105

Das alte und das neue Unterrichtssystem .................................. 107 
VI Inhalt

Lefèvre d'Etaples, Erasmus und Budé ........................................... 109

Die Universitäten und Collèges ................................................... 114

Latein, Mittel- und Neufranzösisch ........................................ 117

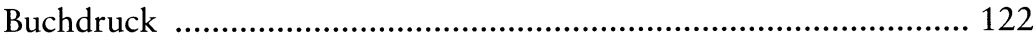

V. Orthodoxie, Reformation und Unglaube

Calvin als Erbe reformatorischer Tendenzen .................................. 128

Reformation und französische Literatur - Rabelais und Calvin ...... 136

Clément Marot ........................................................................... 141

Bonaventure Des Périers ............................................................143

Marguerite de Navarre ............................................................... 150

Henri Estienne: »Apologie pour Hérodote « ............................... 154

VI. Themen der französischen Renaissance-Literatur

Lachen und Komik .................................................................. 157

Der menschliche Körper - Riesen und Zwerge ............................. 164

Das Narrenmotiv ..................................................................... 167

Das Reisemotiv (Utopien) ...................................................... 171

Krieg und Frieden ................................................................... 179

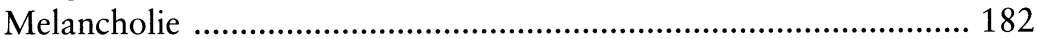

VII. Gattungen der französischen Renaissance-Literatur

Lyrik: Von den Rhétoriqueurs zur Pléiade.................................... 186

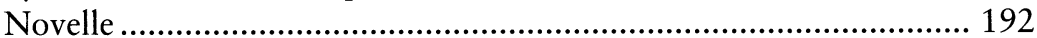

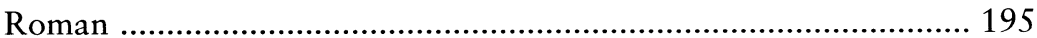

Essay und Geschichtsschreibung .............................................. 196

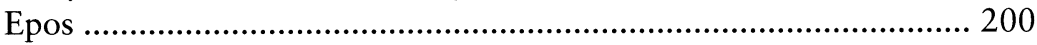

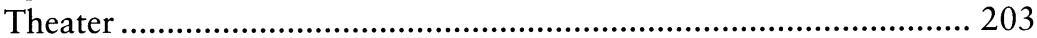

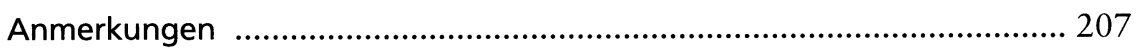

Abkürzungsverzeichnis ............................................................... 224

Bibliographie

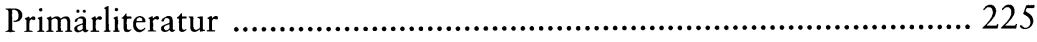

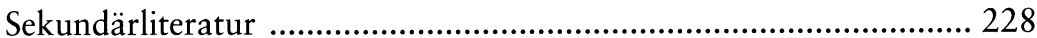

Register der wichtigsten Eigennamen und Werktitel ............................ 233 


\section{VORWORT}

Vor einem Jahr erschien als erstes 'Lehrbuch einer neu konzipierten Reihe ein Band über die Literatur des französischen Mittelalters. Dabei wurde bereits angekündigt, daß weitere Bände folgen sollten. Entgegen dem ursprünglichen Plan erwies sich der Stoff als zu umfassend, um 'Renaissance und Klassik in einem einzigen Band abhandeln zu können, weshalb der zweite Band allein eine Einführung in die französische Literatur der Renaissance enthält. Dies ist auch deshalb sinnvoll, weil die Erforschung der französischen Renaissance inzwischen ein Stiefkind der deutschen Romanistik darstellt, international jedoch - insbesondere durch französische, englische, nordamerikanische und italienische Beiträge - stofflich wie methodisch weit vorangeschritten ist. An der Konzeption der ,Lehrbücher hat sich jedoch nichts geändert. Auf die Übersetzung der ausgewählten Textstellen wurde diesmal allerdings weitgehend verzichtet: Es handelt sich meist um neufranzösische Beispiele, wenn auch um sehr frühe, die auch der sprachhistorisch wenig geübte Benutzer im allgemeinen ohne allzu große Mühe verstehen kann. Es wurden vorzugsweise Abschnitte aus bekannteren Autoren wie Rabelais, Montaigne, Marguerite de Navarre, Ronsard, Du Bellay u.a. ausgewählt, deren Werke in verschiedenen deutschen Übersetzungen vorliegen. Einige werden in der Abschlußbibliographie genannt; genaue Stellenangaben ermöglichen ein Nachschlagen in nicht verzeichneten, aber mit den entsprechenden Hilfsmitteln (z.B. Fromm) schnell zu ermittelnden Übersetzungen.

Bei der Darstellung literaturhistorischer Sachverhalte greife ich gelegentlich auf das 4. Kapitel der im Metzler-Verlag erschienenen und von Jürgen Grimm herausgegebenen Französischen Literaturgeschichte (Stuttgart-Weimar 31994, S. 100-135) zurück, das ich selber verfaßt habe und das in der Argumentation gestrafft und vor allem um Angaben zu weiterführender Literatur und einschlägige Textpassagen ergänzt wird. Auch hier kann wieder nur eine repräsentative Auswahl geboten und nicht Vollständigkeit erreicht werden. In erster Linie werden Monographien angegeben, die ihrerseits wieder weiterführende Literaturangaben enthalten. Auch dieser Band wendet sich nicht an den Forscher und Spezialisten, sondern an den Fachstudenten wie den Interessenten aus anderen Disziplinen, um ihnen den Zugang zu einzelnen Gattungen und bedeutenden Vertretern der französischen Renaissanceliteratur zu erleichtern.

Ich danke dem Metzler-Verlag und seinem Lektorat, daß sie mein Konzept akzeptiert und auch diesen zweiten Band intensiv betreut haben. Besonderen Dank schulde ich Frau Ute Hechtfischer für zahlreiche Anregungen und 
Verbesserungen bei der Lektorierung des Manuskripts. Dank gilt auch meinen Mitarbeitern Max Gröne und Martina Neumeyer für kritische Durchsicht des Manuskripts und wertvolle Verbesserungsvorschläge.

Freiburg, im Februar 1997

Frank-Rutger Hausmann 